\title{
Disgust Promotes Disposal: Souring the Status Quo
}

\section{Citation}

Han, Seunghee, Jennifer S. Lerner and Richard Zeckhauser. 2010. Disgust Promotes Disposal: Souring the Status Quo. Faculty Research Working Paper Series, RWP10-021, John F. Kennedy School of Government, Harvard University.

\section{Published Version}

http://web.hks.harvard.edu/publications/workingpapers/citation.aspx?Publd=7337

\section{Permanent link}

http://nrs.harvard.edu/urn-3:HUL.InstRepos:4449096

\section{Terms of Use}

This article was downloaded from Harvard University's DASH repository, and is made available under the terms and conditions applicable to Other Posted Material, as set forth at http:// nrs.harvard.edu/urn-3:HUL.InstRepos:dash.current.terms-of-use\#LAA

\section{Share Your Story}

The Harvard community has made this article openly available.

Please share how this access benefits you. Submit a story.

Accessibility 


\section{Disgust Promotes Disposal: Souring the Status Quo Faculty Research Working Paper Series}

\section{Seunghee Han}

Carnegie Mellon University

\section{Jennifer S. Lerner}

Harvard Kennedy School

\section{Richard Zeckhauser}

Harvard Kennedy School

\section{J une 2010 RWP10-021}

\footnotetext{
The views expressed in the HKS Faculty Research Working Paper Series are those of the author(s) and do not necessarily reflect those of the John F. Kennedy School of Government or of Harvard University. Faculty Research Working Papers have not undergone formal review and approval. Such papers are included in this series to elicit feedback and to encourage debate on important public policy challenges. Copyright belongs to the author(s). Papers may be downloaded for personal use only.
} 
Running head: DISGUST PROMOTES DISPOSAL

\title{
Disgust Promotes Disposal:
}

\section{Souring the Status Quo}

\author{
Seunghee Han \\ Carnegie Mellon University \\ Jennifer S. Lerner \\ Harvard University \\ Richard Zeckhauser \\ Harvard University
}

Keywords: emotion, disgust, status quo bias, choice, decision making Word Count: 4975

\author{
Contact Information \\ Jennifer S. Lerner, Professor \\ Harvard Kennedy School \\ 79 JFK Street \\ Cambridge, MA 02138 \\ Phone: 617-495-9962 \\ Email: Jennifer_Lerner@harvard.edu
}




\begin{abstract}
Humans naturally dispose of objects that disgust them. Is this phenomenon so deeply embedded that even incidental disgust - i.e., where the source of disgust is unrelated to a possessed objecttriggers disposal? Two experiments were designed to answer this question. Two film clips served as disgust and neutral primes; the objects were routine commodities (boxes of office supplies). Results revealed that the incidental disgust condition powerfully increased the frequency with which decision makers traded away a commodity they owned for a new commodity (more than doubling the probability in each condition), thereby countering otherwise robust status quo bias (Samuelson \& Zeckhauser, 1988). Decision makers were unaware of disgust's impact. Even when warned to correct for it, they failed to do so. These studies presented real choices with tangible rewards. Their findings thus have implications not only for theories of affect and choice, but also for practical improvements in everyday decisions.
\end{abstract}




\section{Disgust Promotes Disposal: Souring the Status Quo}

Charles Darwin (1872) defined disgust as “...something revolting, primarily in relations to the sense of taste..." (p. 253). His analysis treated disgust as a basic emotion along with anger, fear, sadness, and happiness (Ekman \& Davidson, 1994). Indeed, disgust satisfies all the modern criteria of a basic emotion, as articulated by Ekman (1992), encompassing distinctive behavioral, physiological, and expressive components as well as experiential components.

More recent definitions of disgust have stressed its function of triggering rejection of badtasting or health-threatening food (e.g., Angyal, 1941; Ekman \& Friesen, 1975; Frijda, 1986).

Disgust has been assumed to play a role in indicating that a substance should either be avoided or expelled if ingestion has already occurred. Rozin and his colleagues, who have extensively studied the evolution of disgust, extended the concept beyond food-related stimuli by observing that anything that reminds us of our animal origins can elicit disgust (Haidt, McCauley, \& Rozin, 1994; Rozin \& Fallon, 1987; Rozin, Haidt, \& McCauley, 2000). These studies find that, in addition to food, as many as eight domains — including body products, animals, sexual behaviors, contact with death or corpses, violations of the exterior envelope of the body, poor hygiene, interpersonal contamination, and certain moral offenses - can elicit disgust.

This wide range of physical and social elicitors makes disgust a common experience in daily life. It also plays a significant role in affecting behaviors. Heath, Bell, and Sternberg (2001) identified disgust as one of the emotions most frequently evoked by contemporary urban legends that propagate through subcultures and drive mass-scale consumer behavior. For example, rumors of food contamination often elicit social panic. Two recent high-impact advertising 
campaigns drew on disgust to promote public health. First, graphic pictures of smoking related diseases printed on Canadian cigarette packages are reported to have elicited strong disgust from smokers and were correlated with reduced smoking and smoking cessation (Hammond, Fong, McDonald, Brown, \& Cameron, 2004). Second, disgust has been successfully employed in a public campaign for hand washing (Duhigg, 2008). The TV advertisements showed mothers and children walking out of bathrooms with a glowing purple pigment on their hands that contaminated everything they touched. The use of soap after using the toilet increased. Considering its widespread role in society, the effects of disgust on people's everyday choices deserve investigation. To date, however, disgust has received only scant attention in experiments seeking to determine its causal role in individual decision making.

The present studies examine how disgust affects choices between something already possessed and an alternative not yet possessed. Such choices are common, involving, for example, jobs, significant others, and many physical possessions. Under ordinary circumstances, decision makers faced with this sort of choice reliably favor retaining a status quo over other options This status quo bias (SQB) persists even when a current possession has been randomly and/or arbitrarily assigned (e.g., Samuelson \& Zeckhauser, 1988), and even when retaining the status quo option confers financial cost (e.g., Hartman, Doane, \& Woo, 1991).

There are strong reasons to hypothesize disgust might counteract SQB. As with the antismoking campaign described above, we might assume that when an individual associates a current possession with a disgusting experience, the individual will view the possession as less attractive and will be more likely to replace it. If someone receives a foul-smelling package, she is likely to 
favor exchanging it for a fresh one. But what if careful thought causes the owner to understand that the disgusting experience should not in fact influence the attractiveness of the possession? For example, suppose the package's foul smell obviously came from the outside of the box and that the metal object inside was unlikely to be contaminated. Will the offended owner still choose to reject the status quo object in favor of an alternative? Alternatively, what if it became clear that the source of the disgust had nothing to do with the package (e.g., it came from being stored in a closet with a dead mouse)? Would disgust still trigger a desire to dispose of one's possessions? We conjecture that it would.

In the present study, we investigate a strong version of the conjectured carryover effect of disgust. Our two experiments present a "strong" test for the following three reasons. First, we induce disgust in an experimental process rather than having participants experience it in naturalistic form. We believe this lowers the intensity of disgust relative to what one would find in real life. Second, we use objects that have nothing to do with the source of the disgust. Third, we follow standard procedures from experimental economics, including only decisions with tangible consequences, to motivate participants to make decisions carefully and strategically.

\section{Three Alternative Hypotheses}

Based on the literature, at least three alternative hypotheses can be theoretically derived to describe the relationship between disgust and SQB. We start with the null.

\section{Hypothesis 0: Incidental disgust exerts no influence on $S Q B$.}

This pattern may occur for two very different reasons. First, rational decision theory would hold that because incidental disgust is unrelated to the inherent attractiveness of two options, it should have no effect on the choice between them (Raiffa, 1997). Second, influential 
theories of affect and judgment (for a review, see Forgas, 2003) would hold that disgust, a negatively valenced emotion, may elicit a generalized devaluation of both present possessions and potential possessions because negative emotions would trigger generalized negative judgments across judgment domains. If so, when disgusted, decision makers would simply retain the statusquo because both what they presently have and what they might acquire are diminished in value.

If null Hypothesis 0 is refuted, then Hypotheses 1 and 2 -- which predict effects in opposite directions -- should be tested.

\section{Hypothesis 1: Incidental disgust amplifies $S Q B$.}

This hypothesis derives from the classic literature on arousal/social facilitation, which shows that increases in general arousal cause individuals to display their dominant response to the stimulus situation (See, for example, Foster, Witcher, Campell, \& Green, 1998; Zajonc, 1965). Disgust can be considered an emotion that intensifies arousal, if one considers the sympathetic nervous system response on multiple dimensions (Gross \& Levenson, 1993; Levenson, Ekman, \& Friesen, 1990); therefore, it would amplify the dominant response of retaining a status quo possession.

\section{Hypothesis 2: Incidental disgust counteracts $S Q B$.}

This hypothesis derives from the appraisal-tendency framework (ATF; Lerner \& Keltner, 2001; for update, see Han, Lerner, \& Keltner, 2007), which assumes that specific emotions give rise to cognitive and motivational characteristics that can account for the effect of each emotion on individuals' decisions. The ATF posits that disgust, which revolves around the appraisal theme of being too close to an indigestible object or an idea (for elaboration, see Lazarus, 1991), 
will evoke an implicit tendency to dispose of current objects (Frijda, 1986; Rozin, Haidt, \& McCauley, 2000). If so, even incidental disgust would motivate decision makers to wish to exchange a status quo commodity for a new commodity. Lerner et al. (2004) hypothesize that disgust will also evoke an implicit goal to avoid acquiring anything new. However, in our study, the goal to expel should be stronger, because the disgusting event is both physically and temporally more associated with the status-quo commodity than with the alternative. Thus, disgust would promote disposal of a status quo object, thereby counteracting SQB.

If a disgust-disposal effect is found, it would reinforce an emerging literature demonstrating that emotions can profoundly alter otherwise robust regularities of human decision processes - in the present case, for instance, the preference for a status quo over an alternative (for a review see Loewenstein \& Lerner, 2003). Moreover, it would reinforce surprising findings in the literature that even incidental emotions - i.e., emotions triggered by a factor unrelated to the decision at hand—can reverse people's choices in decisions with real monetary consequences (e.g., Lerner, Small, \& Loewenstein, 2004). In effect, it would add to the growing evidence that emotions have the ability to overpower rational choice processes, thereby influencing decisions to which they have no normative relevance.

We focus exclusively on disgust (as opposed to other negative emotions) because of the interesting questions that arise from the theories outlined above. The hypothesized disposal effect implies that it would contrast with the otherwise robust human tendency to hold on to current objects, as evidenced in SQB.

Finally, if either of the carryover patterns described is found when incidental disgust is induced, it is likely to be a non-conscious process. That is, gut feelings rather than deliberative 
processing would drive the phenomenon. If they do, decision makers will lack clear insight into the emotional influences on their choice (Wilson \& Brekke, 1994). We will test this conjecture about insight and will also study whether calling participants' attention to the phenomenon alters their choices.

\section{Study 1}

Study 1 took the form of a $2 \times 2$ between-subjects factorial in which the emotion condition was crossed with two commodities. The commodities were a square box and an oblong box of approximately equal weight and volume (see Figure 1). The participants were told the boxes contained office supplies of equivalent value. ${ }^{1}$ We presented undisclosed commodities in generic boxes that appeared equivalent in order to facilitate a clean test of the hypotheses, to ensure the results would generalize, and to clarify the decision processes of participants, who had little reason to choose one box over the other.

\section{Method}

Design and participants

One-hundred-and-six individuals (54 males, 50 females, 2 unspecified) from a university community participated in exchange for a $\$ 10$ show-up payment. Participants ranged in age from 16 to $29(M=20)$.

Participants sat in cubicles and could not see each other. They were given instructions that charged them with two separate tasks, which were combined for convenience. Before they began the first task, participants randomly received either an oblong box or a square box. They were told the contents of the box were theirs to keep for participating in the study (see Figure 1). 
Emotion induction. Participants were randomly assigned to either a disgust condition or a neutral condition. Disgust-condition participants watched a previously validated (Lerner et al., 2004) video clip portraying a man using a filthy toilet (from the film Trainspotting). Neutralcondition participants watched a previously validated (Lerner et al., 2004) video clip about the Great Barrier Reef (from a National Geographic special), a nature documentary selected for its neutral effect on emotions. Immediately after watching their clip, participants in the disgust condition were asked to write about how they would feel if they were in the situation depicted, and participants in the neutral condition were asked to write about their daily activities.

Trading decision. To encourage a sense of ownership of the generic boxes, participants were invited to shake their box and guess what kind of office supplies the box might contain. Next, participants were given a new box, which they were also invited to shake. They were told that the new box contained a different kind of office supply that was of equivalent value to that in the old box. Participants were then asked to decide whether to keep the old box or exchange it for the new one. Participants' preferences between the status quo (the old box) and the alternative (the new box) were measured using established paradigms in experimental economics (e.g., Knetsch \& Sniden, 1984).

Manipulation check. Immediately after making the trading decision, participants were asked to report how intensely they felt each of 20 emotions. Four negative emotions were of primary interest: anger, sadness, fear, and disgust.

Final questionnaire. Participants also typed a response to an open-ended question: Why did you choose to exchange/keep the box you were given? These responses were coded by research assistants. Finally, participants answered demographic questions. While participants 
completed the questionnaire, the experimenter exchanged boxes for those who chose to trade. Participants kept the contents of their boxes, which pilot tests revealed to be moderately pleasing.

\section{Results}

Manipulation checks

Emotions were effectively induced, both in magnitude and specificity. Specifically, neutral-condition participants reported feeling significantly more neutral than disgusted $\left(M_{n}=\right.$ 3.72 versus $\left.M_{d}=0.24\right), t(52)=10.44, p<.001$. Disgust-condition participants reported feeling significantly more disgusted than neutral $\left(M_{d}=5.54\right.$ versus $\left.M_{n}=2.32\right), t(52)=6.49, p<.001$. They also reported feeling significantly more disgust than the other primary negative emotions: anger $\left(M_{a}=0.87, S D=1.17\right)$ and sadness $\left(M_{s}=1.02, S D=1.53\right)$.

\section{Main analyses}

Trading propensities. The data were analyzed using logistic regressions. Regardless of which commodity was randomly chosen to serve as the status quo, disgust-condition participants were significantly more likely $(50.9 \%)$ to trade away their status-quo commodity than were neutral-condition participants (32.1\%). The difference was significant: Wald $\chi^{2}(1, \mathrm{~N}=106)=$ $4.778, p<.05, \Phi=.21$.

Note the significant status quo bias in the neutral condition; less than a third of these participants traded away their item. Comparing the two box conditions, it is worth pointing out that participants were less willing to trade away the oblong box than the square box, suggesting an unpredicted preference for the oblong box, other factors held equal (see Table 1). A critical baseline finding for us, however, is that the difference in the propensity to trade was virtually identical across the two types of boxes. 
Support for main hypothesis. Our results reject Hypotheses 0 and 1, and support Hypothesis 2. Relative to a neutral state, incidental disgust makes decision makers more likely to exchange a status quo commodity for a new commodity. This statistically significant effect of disgust on choice remained the same even when self-reported anger was entered in the equation as a covariate $\chi^{2}(1, \mathrm{~N}=106)=4.871, p<.05$. The same was true when sadness $\chi^{2}(1, \mathrm{~N}=106)=$ $4.649, p<.05$, or anger and sadness together $\chi^{2}(1, \mathrm{~N}=106)=4.888, p<.05$, were entered as covariates. These results indicate that other negative emotions measured in the study, sadness and anger, did not explain additional variance in the observed disgust effect.

Disgust thereby counteracts SQB. The effect size was substantial $(\Phi=.21)$, as reported above. Disgust more than doubled the propensity to exchange (oblong box) and raised it by more than half (square box), in accordance with the ATF prediction.

Rationales for choices. Participants' explanations for choosing their preferred box were coded; the explanations conveyed no awareness of emotional carryover. Apart from "random choice," the most common rationales for choosing a box were: "makes a more interesting noise," (21\%) "feels more useful,"(28\%) and “feels heavier.”(21\%)

\section{Discussion}

Study one, using two virtually generic commodities, found that disgust can drive choice even when decision makers have no good reason to prefer one item over another. Perhaps surprisingly, participants reported no influence of disgust on their choices, but identified other barely relevant characteristics as influences. 


\section{Study 2}

Carryover effects of disgust were solidly established in Study 1. To gauge the potential importance of the phenomenon, Study 2 sought to examine whether decision makers can selfcorrect for it when made aware of the possible carryover effects. Wilson and Brekke's authoritative review (1994) of judgment and decision biases identifies four factors necessary for bias correction: 1) awareness of unwanted processing; 2) awareness of direction and magnitude of the bias; 3 ) motivation to correct bias; 4) ability to adjust response. Study 2 will provide the first three of these factors in an effort to observe whether decision makers can adjust their responses. If, after providing all three factors, we observe no carryover, then we can conclude that disgusted decision-makers are indeed able to correct the carryover. The phenomenon may hold less import if it is easily corrected. We hypothesize, however, that the carryover of disgust will remain. If correcting the disgust-disposal effect requires mentally disentangling the incidental disgust prime from the choice objects, then the disgust-disposal effect, which seemed to be driven by gut feelings rather than deliberative processing, is unlikely to be corrected even when decision makers' attention is called to the phenomenon. Thus, we propose:

Hypothesis 3: An otherwise effective warning will not negate the disgust-disposal effect.

\section{Method}

Study 2 took the form of a $2 \times 2$ between-subjects factorial in which the emotion condition was crossed with a warning. We made the oblong box the status quo, thus avoiding consideration of a further experimental factor (in Study 1, the results for both boxes supported Hypothesis 2). Moreover, since the oblong box produced a higher ratio of trade behavior 
between the disgust and neutral conditions, it allowed more potential to find a warning effect for disgust.

Design and participants

One-hundred-and-twenty university students ( 74 males, 45 females, 1 unspecified) participated in exchange for class credit. Participants' ages ranged from 18-25 $(M=20)$. Procedures matched those of Study 1, except as noted.

Warning. After the emotion induction and before making their choices, half the participants received the following written warning regarding emotional carryover from the film clip they had just seen:

Watching film clips in the first part of the study can bias choices in the second part. Specifically, having just seen an unpleasant film can increase your desire to get rid of things you have in your possession. Likewise, having just seen a pleasant film clip can increase your desire to keep things you have in your possession. Because we are interested in studying how people can avoid being biased, please try your absolute best to avoid having any influence of the film clip on your decisions about the box! Give us your honest choice, reflecting your own feelings about the box, regardless of the film clip you viewed.

In the warning, the films were referred to as "pleasant" and "unpleasant," corresponding to the neutral and disgust conditions respectively. ${ }^{2}$ The warning specified the direction of potential bias: pleasant films (neutral condition) create a bias toward retaining the object possessed, whereas unpleasant firms (disgust condition) create a bias toward getting rid of the object. Everyone in a warning condition received the text above.

Trading decision. Following Study 1's methods, subjects were then given the second box, allowed to handle/shake it, and asked whether they wished to make a trade. ${ }^{3}$

\section{Results}




\section{Manipulation check}

Emotion inductions were effective in magnitude and specificity. Neutral-condition participants reported feeling significantly more neutral than disgusted $\left(M_{n}=3.30\right.$ versus $M_{d=}$ 0.43 respectively), $t(60)=3.07, p=.003$. Disgust-condition participants reported feeling significantly more disgusted than neutral $\left(M_{d}=3.68\right.$ versus $M_{n}=2.37$ respectively), $t(58)=$ $6.49, p<.001$. Disgust-condition participants also reported feeling significantly more disgust than any other measured negative emotion, including anger and sadness. These results were consistent with Study 1.

The warning was noted by participants: $91.7 \%$ said they remembered the warning about the possible biasing effects of the film, and $87.2 \%$ said the warning was believable.

\section{Main analyses}

The data were analyzed using logistic regressions. In the no-warning (control) conditions, Study 1's pattern was replicated. Consistent with the main hypothesis, disgust-condition participants were much more likely (33.3\%) to trade away their status-quo commodity than were neutral-condition participants (13.8\%). In the warning condition, the predicted asymmetric pattern emerged. As was required for this test to be meaningful, neutral-condition participants heeded the warning, thus establishing appropriate conditions for the test of Hypothesis 3 . That is, neutral-condition participants (who were warned that the clip would bias them toward retaining their commodity) adjusted their choices as instructed, trading more frequently in the warning condition $\left(\mathrm{M}_{\mathrm{n}}{ }^{\mathrm{no-warning}}=13.8 \%, M_{\mathrm{n}}{ }^{\text {warning }}=37.5 \%\right)$, Wald $\chi^{2}(1, \mathrm{~N}=61)=4.127, p<$ $.05, \Phi=.26$. 
Our prime interest was the effect of the warning (that the clip would bias them toward trading away their commodity) on disgust-condition participants. We predicted a modest effect at best, and that is what we found. Participants traded at the same rate independent of the warning manipulation $\left(M_{\mathrm{d}}{ }^{\text {no-warning }}=33.3 \%, M_{\mathrm{d}}{ }^{\text {warning }}=31.0 \%\right)$, Wald $\chi^{2}(1, \mathrm{~N}=59)=0.36$, see Table 2). This result supports Hypothesis 3; namely, even warnings that are effective elsewhere do not negate the disgust-disposal effect. ${ }^{4}$

As in Study 1,90\% of the participants in the disgust condition, whether warned or not, reported that viewing the unpleasant movie clip could not have influenced their own preferences. Yet because of the clip, both warned and unwarned groups increased their propensity to trade.

As a check on reliability, a descriptive set of analyses compared trading from Study 1 with trading levels in Study 2. In order to create a clean, unconfounded comparison, we included only the conditions in Study 1 that had an oblong box as the initial possession (Study 2 used only oblong boxes). As expected, comparing the trading level for the disgust condition across studies yielded no significant differences (42.3\% in Study 1 versus $33.3 \%$ in Study 2 ). Also as expected, comparing the trading level for the neutral condition yielded no significant differences (21.1\% in Study 1 versus $13.8 \%$ in Study 2 ).

\section{Discussion}

To recap, neutral-condition decision makers heeded the warning and engaged in substantially more trades when warned. ${ }^{5}$ By contrast, disgust-condition decision makers traded away their status-quo commodity at the same rate whether or not they were warned against carryover effects. This evidence supports our conjecture that the disgust-disposal effect 
operates at such a basic level that it persists even in the presence of measures that would normally diminish them. ${ }^{6}$

The robust effect of incidental disgust observed here may appear at odds with previous findings suggesting that incidental emotion effects tend to be fragile and often go away once an individual's attention is drawn to the potential bias. For example, Schwarz \& Clore (1983) found that when an individual's attention was drawn to weather, its effect on subjective well-being disappeared. It should be pointed out, though, that whereas people might readily admit the effect of sunny weather on their sense of well-being, they might be unwilling to admit, whether to themselves or others, the effect of irrelevant disgust on the choice between the two objects. In fact, participants in the present study reported that while the warnings made sense, they did not believe that their own choice between the two boxes was influenced by watching the disgusting film clip. That is, the warning did not match participants' awareness of their subjective experience. Thus, unlike in the affect-as-information tradition (e.g., Schwarz \& Clore, 1983), the warnings here were unlikely to have been acknowledged and heeded - a difference that we speculated about above and that merits future examination.

\section{General Discussion}

Incidental feelings of disgust carry over to promote the disposal of currently owned objects unrelated to the induced disgust, and thus counteract SQB. We call this the disgustpromotes-disposal effect. The effect is substantial. Across studies and conditions, disgusted people were between $55 \%$ and $141 \%$ more likely to dispose of a present possession than were people in an unwarned neutral state. A warning that changed behavior for those in the neutral state did not diminish the disgust-promotes-disposal effect. Interestingly, disgust-condition 
participants denied any influence of the disgust-inducing agent (a film clip) on their choices. Rather, they attributed their choices to rational, deliberative preferences, such as a fondness for oblong boxes. This finding is consistent with the ATF hypothesis that, through a subconscious process, disgust triggers the implicit goal to dispose of current possessions and thus counteracts SQB. The results add empirical evidence to the growing body of work demonstrating that specific emotions have a powerful effect on choices. Is the effect specific to disgust?

One may wonder whether the observed effect is specific to disgust or whether it applies to negative emotions in general. As was demonstrated in the manipulation check data, the disgust induction elicited discrete feelings of disgust rather than general negativity. It did not make participants either angry or sad. As an additional check, further analysis revealed that other negative emotions measured in the study, sadness and anger, do not explain additional variance in the observed disgust effect. Therefore, it appears that the increased disposal of the status quo object observed in the current studies is attributable to disgust and not to other negative emotions.

The possibility remains that other emotions may be able to produce a similar effect on SQB. If so, we suspect that this would occur through a different mechanism. For example, one could hypothesize that anger may counteract SQB. Anger is associated with relative left frontal hemispheric activation in the brain - a pattern characteristic of approach motivation (HarmonJones, 2003). Anger may motivate decision makers to take actions and exchange current objects. In a different realm, one could hypothesize that social disgust (e.g., disgust over immoral action) may produce the same effect as physical disgust. (For a comprehensive review of different kinds of disgust, see Rozin, Haidt, \& McCauley, 2000.) Data from an f-MRI study 
support this speculation. Increased activation in the anterior insula, a brain structure known to be involved in the experience of physical disgust (Phillips et al., 1997; Wicker et al., 2003), predicted participants' decisions to reject unfair offers from their partners (Sanfey, Rilling, Aronson, Nystrom, \& Cohen, 2003). This suggests that social disgust may in fact share the same neural mechanisms as physical disgust, and thus may produce the same effect. These interesting possibilities are beyond the scope of this paper and will hopefully be examined in future studies. Is the effect strong enough to reverse $S Q B$ ?

One might wonder whether the disgust effect has the potential to be strong enough to reverse SQB, which has generally been shown to be substantial. The question of whether disgust would reverse or merely reduce SQB depends on the strength of both effects. Our disgust induction was modest in three respects: (a) it was generated by a movie that was tangentially related (at most) to the possessed object; (b) there was no taste or smell associated with the disgust induction, sensations that would likely increase the level of disgust; and (c) the object itself was neutral and in no way connected to items that might induce disgust, such as food. If the object had been related to consumption rather than office supplies, the disposal effect might have been much greater. It might even have been greater if participants had viewed the office supplies rather than being presented with them in a sealed box. Therefore, even though we only observed reductions in SQB, we do not rule out a possibility that in other contexts disgust could cause a reversal in SQB.

\section{Practical Implications}

The finding that disgust promotes disposal has real-world implications that range from the minor to the monumental. In a broad array of cases, people's propensity to stick with the 
status quo could be powerfully counteracted by feelings of incidental disgust. In practice, the link between disgust and disposal will be more common when disgust is integral rather than incidental to the decision at hand, though more difficult to isolate. Thus, a senior citizen who bathes insufficiently may suffer more social isolation than mere foul smell would seem to merit, perhaps accelerating a health decline via lack of social support (e.g., Hegelson \& Cohen, 1996). Similarly, a cancer patient who is nauseated by chemotherapy drugs may be too inclined to switch to alternative treatments, to her detriment. Transcending theoretical models of emotion and decision making, the implications of our findings apply to many of life's choices. 


\section{References}

Angyal, A. (1941). Disgust and related aversions. Journal of Abnormal and Social Psychology, 26, 393-412.

Darwin, C. R. (1965). The Expression of the Emotions in Man and Animals. Chicago: University of Chicago Press. (Original work published 1872).

Duhigg, C. (2008, July 13). Warning: Habits maybe good for you. The New York Times.

Ekman, P. (1992). An argument for basic emotions. Cognition and Emotion, 6, 169-200.

Ekman, P., \& Davidson, R. J. (1994). The nature of emotion: Fundamental questions. New York, NY: Oxford University Press.

Ekman, P., \& Friesen, W. V. (1975). Unmasking the face. New York: Prentice Hall.

Forgas, J. P. (2003). Affective influences on attitudes and judgments. In R. J. Davidson, K. R. Scherer \& H. H. Goldsmith (Eds.), Handbook of Affective Science (pp. 596-218). New York: Oxford University Press.

Foster, C. A., Witcher, B. S., Campbell, W. K., \& Green, J. D. (1998). Arousal and attraction: Evidence for automatic and controlled processes. Journal of Personality and Social Psychology, 74, 86-101.

Frijda, N. H. (1986). The emotions. New York: Cambridge University Press.

Gross, J. J., \& Levenson, R. W. (1993). Emotional suppression: Physiology, self-report, and expressive behavior. Journal of Personality and Social Psychology, 64(6), 970-986. 
Haidt, J., McCauley, C. R., \& Rozin, P. (1994). Individual differences in sensitivity to disgust: A scale sampling seven domains of disgust elicitors. Personality and Individual Differences, 16, $701-713$.

Hammond, D., Fong, G.. T., McDonald, P. W., Brown, S., \& Cameron, R. (2004). Graphic Canadian cigarette warning labels and adverse outcomes: evidence from Canadian smokes. American Journal of Public Health, 94(8), 1442-1445.

Han, S., Lerner, J.S. \& Keltner, D. (2007). Feelings and consumer decision making: Extending the Appraisal-Tendency Framework. Journal of Consumer Psychology, 17, 184-187.

Harmon-Jones, E. (2003). Clarifying the emotive funtions of asymmetrical frontal cortical activity. Psychophysiology, 40, 838-848.

Hartman, R., Doane, M. J., \& Woo, C. (1991). Consumer rationality and the status quo. The Quarterly Journal of Economics, 106(1), 141-162.

Heath, C., Bell, C., \& Sternberg, E. (2001). Emotional selection in memes: the case of urban legends. Journal of Personality and Social Psychology, 81(6), 1028-1041.

Helgeson, V. S., \& Cohen, S. (1996). Social support and adjustment to cancer: Reconciling descriptive, correlational, and intervention research. Health Psychology, $15,135-148$.

Knetsch, J. L. (1989). The endowment effect and evidence of nonreversible indifference curves. American Economic Review, 79(5), 1277-1284.

Knetsch, J. L., \& Sniden, J. A. (1984). Willingness to pay and compensation demanded: Experimental evidence of an unexpected disparity in measures of value. Quarterly Journal of Economics, 99, 507-521. 
Lazarus, R. S. (1991). Emotion and adaptation. New York: Oxford University Press.

Lerner, J. S., Dahl, R. E., Hariri, A. R., \& Taylor, S. E. (in press). Facial expressions of emotion reveal neuroendocrine and cardiovascular stress responses. Biological Psychiatry.

Lerner, J. S., Small, D. A., \& Loewenstein, G. F. (2004). Heart strings and purse strings: Carryover effects of emotions on economic decisions. Psychological Science, 15(5), 337 341.

Lerner, J. S., \& Keltner, D. (2001). Fear, anger, and risk. Journal of Personality and Social Psychology, 81(1), 146-159.

Lerner, J. S., \& Tiedens, L. Z. (2006). Portrait of the angry decision maker: How appraisal tendencies shape anger's influence on cognition. Journal of Behavioral Decision Making, 19, 115-137.

Levenson, R. W., Ekman, P., \& Friesen, W. V. (1990). Voluntary facial action generates emotionspecific autonomic nervous system activity. Psychophysiology, 27(4), 363-384.

Loewenstein, G., \& Lerner, J. S. (2003). The role of affect in decision making. In R. Davidson, K. Scherer \& H. Goldsmith (Eds.), Handbook of Affective Science (pp. 619-642). London: Oxford University Press.

Morales, A. C., \& Fitzsimons, G. J. (2007). Product Contagion: Changing Consumer Evaluations Through Physical Contact with 'Disgusting' Products, Journal of Marketing Research, 44, 272-283.

Raiffa, H. (1997). Decision Analysis: Introductory Lectures on Choices Under Uncertainty. McGraw-Hill College Custom Series.

Rozin, P., \& Fallon, A. (1987). A perspective on disgust. Psychological Review, 94, 23-41. 
Rozin, P., Haidt, J., \& McCauley, C. (2000). Disgust. In M. Lewis \& J. Haviland (Eds.), Handbook of emotions (2 ${ }^{\text {nd }}$ ed., pp.637-653). New York: Guilford Press.

Samuelson, W., \& Zeckhauser, R. (1988). Status quo bias in decision making. Journal of Risk and Uncertainty, 1, 7-59.

Sanfey A.G., Rilling J. K., Aronson, J. A., Nystrom, L. E., \& Cohen, J. D. (2003). The neural basis of economic decision-making in the Ultimatum Game. Sceince, 300, 1755-1758.

Schnall, S., Haidt, J., Clore, G., \& Jordan, A. (2008). Disgust as embodied moral judgment. Personality and Social Psychology Bulletin, 34, 1096-1109.

Schwarz, N., \& Clore, G. L. (1983). Mood, misattribution and judgments of well-being: Informative and directive functions of affective states. Journal of Personality and Social Psychology, 45(3), 513-523.

Tiedens, L. Z., \& Linton, S. (2001). Judgment under emotional certainty and uncertainty: The effects of specific emotions on information processing. Journal of Personality and Social Psychology, 81, 973-988.

Wheatley, T., \& Haidt, J. (2005). Hypnotically induced disgust makes moral judgments more severe. Psychological Science, 16, 780-784.

Wilson, T. D., \& Brekke, N. (1996). Mental contamination and mental correction: Unwanted influences on judgments and evaluations. Psychological Bulletin, 116(1), 117-142.

Zajonc, R. B. (1965). Social facilitation. Science, 149, 269-149. 


\begin{abstract}
Authors' Note
Grants from the National Institute for Mental Health (MH62376) and the National Science Foundation (PECASE SES0239637; SES0820441) awarded to Jennifer S. Lerner supported this research. We thank Dan Feiler, Bill Mangan, and Sarah Scholl for research assistance. We thank David DeSteno and Yoel Inbar for comments on an earlier draft.
\end{abstract}




\section{Footnotes}

1. In a pilot study where a sporty water bottle and a highlighter set were used as the statusquo and alternative commodities, $39 \%$ of disgust-condition participants traded away the status-quo commodity, whereas only $11 \%$ of neutral-condition participants traded it away, $\chi^{2}(1, \mathrm{~N}=41)=4.04, p<.05, \Phi=.31$.

2. These particular terms were used for two reasons: (1) withholding a label for the target emotion (disgust) reduced demand characteristics associated with it; and (2) pilot testing for the warning revealed that even though participants subjectively experienced the neutral film (coral reef) as neutral, they verbally referred to the neutral film as a "pleasant film" rather than as a "neutral film" because they were not accustomed to thinking of a film as "neutral."

3. There was one difference. In Study 1, participants hung up a card saying "Trade" if they wished to do so. Study 2 made this format more balanced by giving them a second card saying "Keep" to hang if that was their preferred action.

4. An alternative explanation is that decision makers in the disgust condition eschewed the warning because they were angry at the experimenter for making them watch the unpleasant film clip. This idea was empirically tested and received no support. On a scale of 0 to 8 , where 0 meant not experiencing the emotion at all, decision makers in both the disgust and neutral condition reported experiencing almost no anger whatsoever $\left(M_{\mathrm{n}}=\right.$ $\left.0.51, M_{\mathrm{d}}=0.86\right)$

5. The effectiveness of the warning is notable, as there is no reason to believe that pleasant films do promote SQB. 
6. Another possibility is that incidental disgust may have promoted feelings of certainty that inhibited the careful cognitive effort needed to inhibit the disgust-promotes-disposal effect. Specific emotions are reliably associated with particular sets of appraisals along such conceptual dimensions as pleasantness, control, responsibility, and certainty (Roseman, 1984; Scherer, 1982; Smith \& Ellsworth, 1985; Smith \& Lazarus, 1983). In the case of disgust, people tend to strongly experience appraisals of certainty, in addition to appraisals along other dimensions (e.g., negative experience). That is, they have a sense of knowing as opposed to a sense that they should question themselves. Directly relevant to the present study, emotions characterized by a sense of certainty have been shown to promote heuristic cognitive processing rather than systematic cognitive processing (Tiedens \& Linton, 2001). If correcting the disgust-disposal effect requires carefully disentangling the incidental disgust prime from the choice objects, then correction should be less likely to occur among disgusted participants who engage in heuristic processing due to their heightened sense of certainty than among those in a neutral state. 
Table Captions

Table 1. Propensities to Trade Away Status-Quo Object in Study1

\begin{tabular}{c|c|c|c}
\hline Status-Quo Object & Neutral Condition & Disgust Condition & Difference \\
\hline Oblong Box & $21.1 \%$ & $42.3 \%$ & $21.2 \%$ \\
\hline Square Box & $38.2 \%$ & $59.3 \%$ & $21.1 \%$ \\
\hline Across the Two Boxes & $32.1 \%$ & $50.9 \%$ & $18.8 \%$ \\
\hline
\end{tabular}

Table 2. Propensities to Trade Away Status-Quo Object in Study 2

\begin{tabular}{c|c|c|c}
\hline \multirow{2}{*}{ Emotion } & \multirow{2}{*}{ De-Bias Condition } & \multicolumn{2}{|c}{ Choice } \\
& & Keep & Trade \\
\hline \multirow{2}{*}{ Neutral } & No Warning & $86.2 \%$ & $13.8 \%$ \\
\cline { 2 - 4 } & Warning & $62.5 \%$ & $37.5 \%$ \\
\hline \multirow{2}{*}{ Disgust } & No Warning & $66.7 \%$ & $33.3 \%$ \\
\cline { 2 - 4 } & Warning & $69.0 \%$ & $31.0 \%$ \\
\hline
\end{tabular}




\section{Figure Captions}

Figure 1. The square and oblong boxes used in the studies

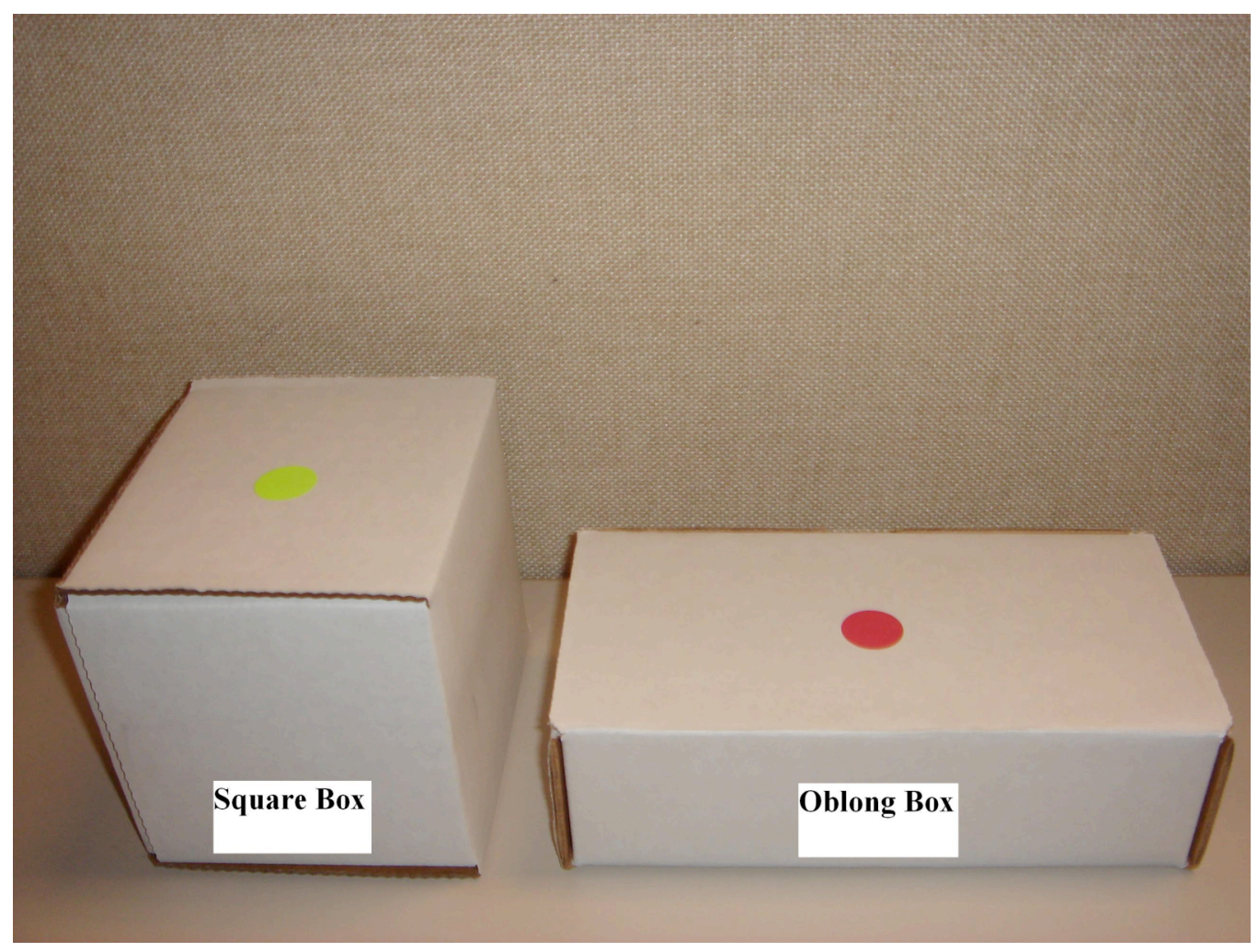

